\title{
PROXIMAL HUMERAL FRACTURES TREATED WITH OSTEOSYNTHESIS USING THE ANTEROLATERAL APPROACH
}

\author{
FRATURA DO ÚMERO PROXIMAL TRATADAS COM OSTEOSSÍNTESE \\ PELA VIA DE ACESSO ANTEROLATERAL
}

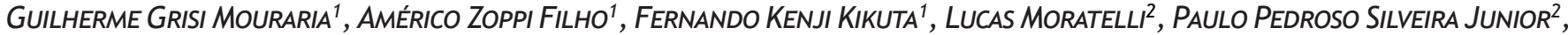 \\ MAURÍCIO ETCHEBEHERE ${ }^{2}$
}

1. Shoulder and Elbow Group, Orthopedics and Traumatology Department, Faculdade de Ciências Médicas, Universidade Estadual de Campinas (UNICAMP), Campinas, SP, Brazil. 2. Orthopedics and Traumatology Department, Faculdade de Ciências Médicas, Universidade Estadual de Campinas (UNICAMP), Campinas, SP, Brazil.

\section{ABSTRACT}

Objective: The main surgical approach in proximal humeral fractures is the deltopectoral approach. Many surgeons avoid the anterolateral approach, fearing its complications, especially axillary nerve injury. The objective of this study is to evaluate shoulder function and complications in patients with proximal humeral fractures treated using an anterolateral approach with direct observation of the axillary nerve. Methods: Retrospective study with postoperative radiological and functional evaluations (Constant and DASH scores) and review of the complications. The associations between fracture classification and the difference in Constant scores among the subjects and the final angle of consolidation were analyzed using Fisher's test or analysis of variance (ANOVA). The Constant scores were compared among the shoulders using the paired t-test. Results: The study evaluated 35 patients. Shoulder function was decreased, compared with the contralateral side $(p<0.005)$. The only factor related to functional worsening was the Neer IV fracture. The main complication was malunion. There were no clinical changes related to the axillary nerve. Conclusion: The treatment using the extended anterolateral approach produced good functional results, although the function was decreased (Neer IV fractures). The main complication was malunion. There were no side effects due to exposure of the axillary nerve. Level of evidence III, Retrospective Study.

Keywords: Humeral Fractures, Surgery, Complications, Osteosynthesis fracture.

\section{RESUMO}

Objetivo: A via de acesso mais utilizada na osteossíntese das fraturas de úmero proximal é a deltopeitoral. A via anterolateral sofre resistência, pois muitos temem suas complicações, principalmente lesão do nervo axilar. Objetivo é avaliar a função do ombro e as complicações nas fraturas de úmero proximal, tratados pela via anterolateral com observação direta do nervo axilar. Métodos: Estudo retrospectivo com avaliação radiológica e funcional (Constant e DASH scores) pós-operatórios e complicações. A associação entre a classificação da fratura e a diferença dos escores entre os membros, bem como o ângulo final de consolidação, foram analisados pelo Teste de Fisher ou Anova. A comparação dos escores Constant entre os membros foi conduzida pelo teste $t$ pareado. Resultados: foram avaliados 35 pacientes. Houve diminuição da função do ombro em relação ao contralateral $(p<0,005)$. O único fator relacionado à piora funcional foi fratura Neer IV. A principal complicação foi consolidação viciosa. Não se observou alterações clínicas relacionadas ao nervo axilar. Conclusão: A osteossíntese das fraturas do úmero proximal realizada pela via de acesso anterolateral estendida, apesar da diminuição da função do ombro (fraturas Neer IV), evoluiu com bom resultado funcional e mostrou-se segura na proteção do nervo axilar. Nível de evidência III, Estudo Retrospectivo.

Descritores: Fixação interna de fraturas, fraturas do úmero proximal, complicações, cirurgia.

Citation: Mouraria GG, Zoppi Filho A, Kikuta FK, Moratelli L, Silveira Jr PP, Etchebehere M. Proximal humeral fractures treated with osteosynthesis using the anterolateral approach. Acta Ortop Bras. [online]. 2019;27(3):173-7. Available from URL: http://www.scielo.br/aob.

\section{INTRODUCTION}

Fractures of the proximal humerus are more prevalent in elderly patients with osteoporosis, and the incidence of these lesions has increased with the aging population. ${ }^{1}$ Neer classified fractures of the humerus based on the deviation of the fragments. Fractures in two to four parts are preferably treated with osteosynthesis when they require surgical treatment. ${ }^{2}$ For fractures affecting the humeral head or fractures in four parts associated with osteoporosis and advanced age, arthroplasty may be the surgical treatment of choice., ${ }^{2,3}$

Osteosynthesis underwent a major evolution with the introduction of fixed-angle locking plates, which provide better fracture stabilisation

All authors declare no potential conflict of interest related to this article. 
in osteoporotic bones compared with conventional plates and have become the implant of choice in osteosynthesis. ${ }^{1}$

The approach most commonly used for the surgical treatment of proximal humerus fractures is the deltopectoral approach due to its ease and reduced proximity to the axillary nerve., ${ }^{1,4}$ Gardner described the anterolateral approach for proximal humerus fractures. ${ }^{5}$ It is performed between the anterior and middle portions of the deltoid, with better exposure of the lateral humerus. Therefore, the anterolateral approach provides better access to the greater tuberosity and the lateral side of the humerus, which facilitates placement of the locking plate as the implant has a fixed angle. ${ }^{5}$ The major risk of the anterolateral approach is damaging the axillary nerve, which runs perpendicular to the humerus, located $5 \mathrm{~cm}$ above the acromion. Therefore, the axillary nerve must be dissected when this approach is used. ${ }^{6-8}$

There are numerous articles on the minimally invasive plate osteosynthesis (MIPO) technique using the anterolateral approach, without axillary nerve isolation, with good functional results. ${ }^{4,9}$ However, few studies have evaluated the safety and function of the shoulder in proximal humeral fractures treated surgically with a locking plate via the anterolateral approach with direct axillary nerve isolation. . $^{510}$ Therefore, this study evaluated the function of shoulders with proximal humeral fractures treated with osteosynthesis with a locking plate via the extended anterolateral approach and examined its complications.

\section{MATERIALS AND METHODS}

This study was approved by the local ethics committee (approval no. 41229014.2.0000.5404).

This retrospective study enrolled patients with proximal humeral fractures classified as Neer 2, 3, or 4 requiring surgical treatment. Patients were excluded if they had fractures associated with dislocations, opposite shoulder injuries that did not allow comparison, or fractures with indications for arthroplasty, or if they refused to participate in the study. All participants have signed a consent form. Osteosynthesis was performed with a locking plate via the extended anterolateral approach. The patients were positioned in a beach chair. A $10-\mathrm{cm}$ incision was made, beginning at the anterolateral edge of the acromion and extending distally parallel to the axis of the diaphysis. (Figure 1) The anterior and middle portions of the deltoid were separated by blunt dissection, the axillary nerve was identified and protected, and the plate was placed below it. (Figure 2)

The bone consolidation and angulation were evaluated with radiographs from three views using the reference values described by Sohn et al., ${ }^{11,12}$ including the true anteroposterior view $\left(20^{\circ}\right.$ of external rotation) for evaluating the head-shaft angle and the axillary view for evaluating anteroposterior angulation. A varus deformity was defined as an angle of less than $120^{\circ}$, and a valgus deformity was defined as an angle greater than $140^{\circ}$. The anterior or posterior tilt of the humeral head was evaluated in the axillary view. Positive values exceeding $5^{\circ}$ were considered anterior tilt, and negative values exceeding $5^{\circ}$ were considered posterior tilt. Values between $-5^{\circ}$ and $+5^{\circ}$ were considered adequate. (Figure 3 ) The reduction of the greater tuberosity was assessed by measuring the distance between the articular surface and the lateral superior aspect of this structure. The height of the plate was evaluated by measuring the distance from the upper border of the greater tuberosity and the apex of the plate. (Figure 3) The consolidation was considered complete when there was callus formation in all three views. The radiographic evaluation was performed independently by two independent surgeons who met to resolve any discrepancy in the evaluations.

Shoulder function was evaluated using the Constant and DASH scores. ${ }^{13}$ The scores of the operated and contralateral sides were compared. The axillary nerve function was evaluated by testing

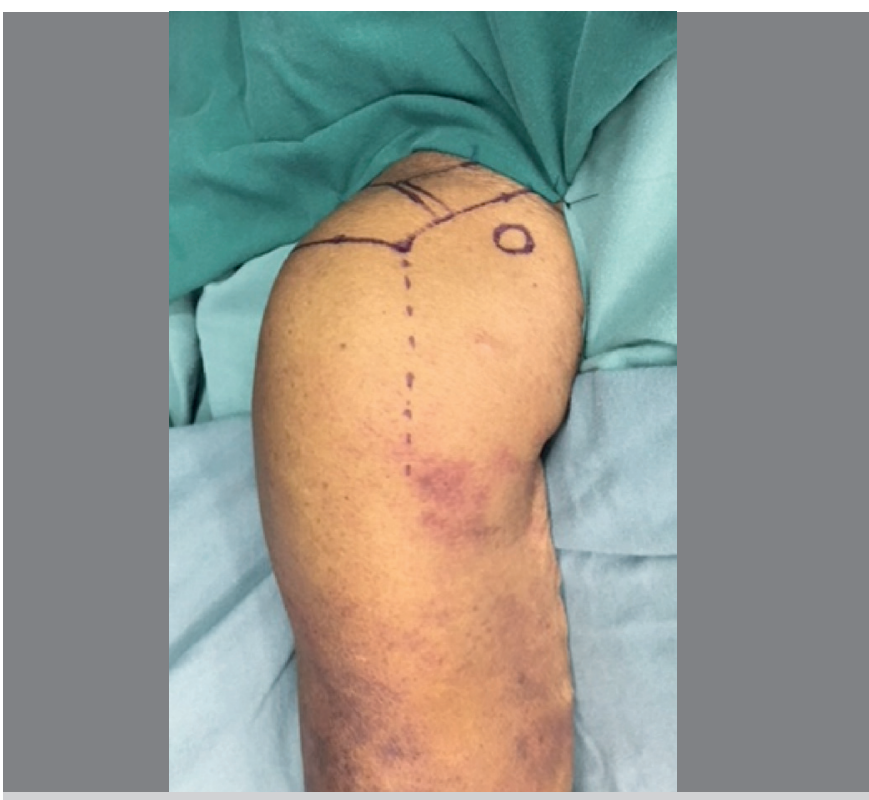

Figure 1. Antero lateral Skin Incision.

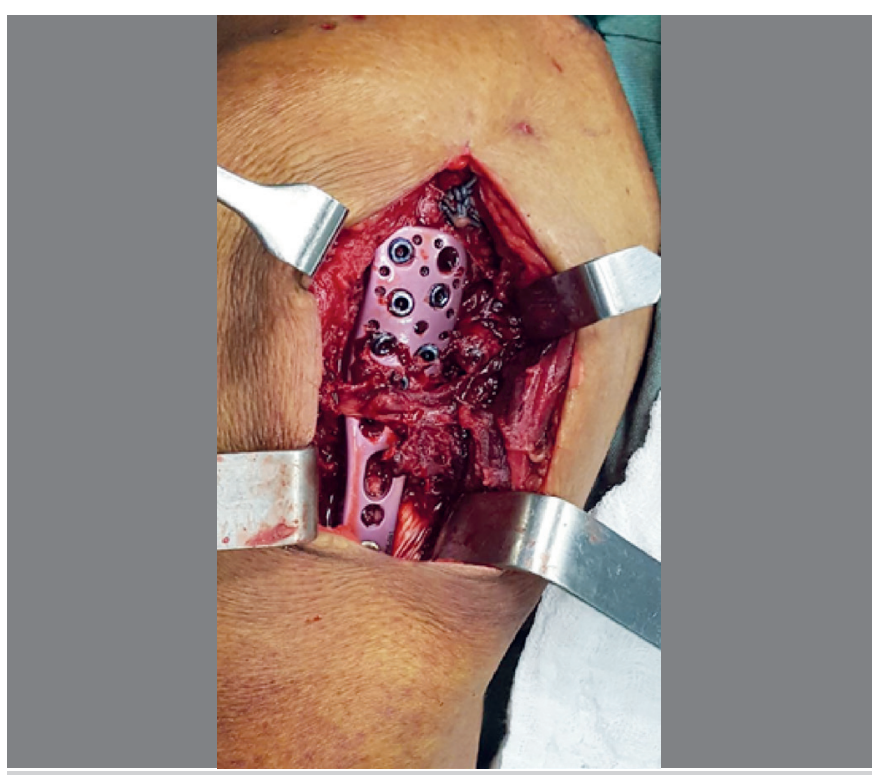

Figure 2. Final plate position

sensation in its dermatome. The evaluations were performed at least 12 months postoperatively.

Factors that could affect shoulder function in these patients were evaluated using multiple linear regression with the stepwise method. The following variables were included in the model: age, gender, fracture classification, affected side, fracture consolidation angle, plaque height and osteonecrosis, and Constant and Dash scores. The fracture classification was treated as a dummy variable. The significance criterion for entering a variable in the model was $5 \%$ in the F-test, and it was $5.1 \%$ significance for its removal. The associations between the fracture classification and the difference in the Constant scores among the subjects and the final angle of consolidation were analysed using Fisher's test or analysis of variance (ANOVA). The Constant scores were compared between the limbs using the paired $t$-test. All analyses were conducted in PASW Statistics 18.0 (SPSS, Chicago, USA), and a significance level of $5 \%(P<0.05)$ was adopted. 


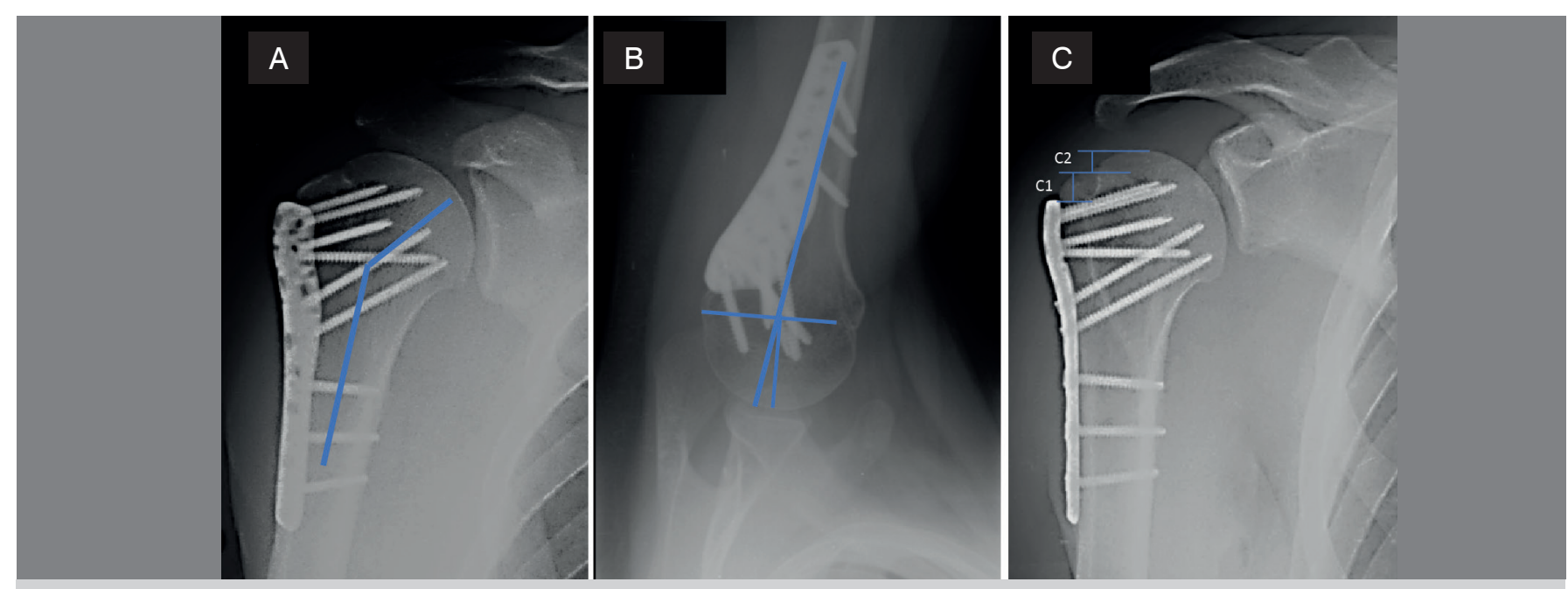

Figure 3. Head-Shaft angle (A); Anteroposterior tilt(B); Plate Height (C1); Greater Tuberosity Reduction (C2).

\section{RESULTS}

We evaluated 45 patients. Ten patients were excluded after they were lost to follow up. There was a predominance of females (54\%). The mean patient age was $53.6 \pm 16.9$ years. The left side (57\%) was most commonly affected. The dominant side was the right in $97 \%$ of the cases.

Of the patients analysed, 11, 13, and 11 were classified as Neer IV, III, and II fractures, respectively. The mean follow-up period was $31.1 \pm 20.3$ months. Consolidation occurred at an average of $3.1 \pm 1.1$ months. There was no case of pseudarthrosis. Table 1 summarises the patients' demographic data.

The final postoperative radiological evaluation showed a headshaft angle of $133.4 \pm 10.1^{\circ}$, and the anteroposterior angulation was $-8.34 \pm 11.23^{\circ}$. The greater tuberosity was $0.93 \pm 5.19 \mathrm{~mm}$ below the articular surface, and the plate was $8.7 \pm 5.19 \mathrm{~mm}$ below the apex of the greater tuberosity. (Table 2) The cases of malunion (14 cases/40\%) involved valgus (3 cases/8.6\%), varus (2 cases/5.7\%), posterior deviation (12 cases/34.3\%), or anterior deviation (1 case/2.9\%). There was no statistical relationship between postoperative angulation and type of fracture. (Table 2) The reduction of the greater tuberosity was adequate in $75 \%$ of the cases (Neer III and IV fractures) and the plate height was adequate in $91.4 \%$ (one case developed impingement and required plate removal). There was no statistical difference in the quality of tuberosity reduction or plate height among the different fracture types. (Table 3)

In one case, the intra-articular screw migrated secondary to osteonecrosis, and the implant was removed. There were no cases involving joint screws in the immediate postoperative period.
One patient developed a superficial infection that was treated with oral antibiotics. Partial osteonecrosis of the humeral head occurred in two patients (one each Neer III and IV). However, neither patient required arthroplasty. In one case, the implant was removed. No patients had decreased sensation in the dermatome corresponding to the axillary nerve.

The mean Constant and DASH scores were $72.1 \pm 16.2$ and $12.1 \pm 15.7$, respectively. The functional evaluation showed a significant

\begin{tabular}{|c|c|}
\hline Variable & Value \\
\hline Age [Mean ( SD)] (years) & $53.6 \pm 16.9$ \\
\hline Consolidation time [mean ( SD)] (months) & $3.1 \pm 1.0$ \\
\hline Follow-up time [mean ( SD] (months) & $31.1 \pm 20.3$ \\
\hline \multicolumn{2}{|l|}{ Gender [No. (\%)] } \\
\hline Male & $16(45.7 \%)$ \\
\hline Female & $19(54.3 \%)$ \\
\hline \multicolumn{2}{|l|}{ Neer Classification [Number. (\%)] } \\
\hline ॥ & $11(31.4 \%)$ \\
\hline III & $13(37.2 \%)$ \\
\hline IV & $11(31.4 \%)$ \\
\hline \multicolumn{2}{|l|}{ Side [Number. (\%)] } \\
\hline Right & $15(42.9 \%)$ \\
\hline Left & $20(57.1 \%)$ \\
\hline \multicolumn{2}{|l|}{ Dominant side [No. (\%)] } \\
\hline Right & $34(97.1 \%)$ \\
\hline Left & $1(2.9 \%)$ \\
\hline
\end{tabular}

Table 2. Numerical variables (mean $\pm \mathrm{SD}$; median [min-max])

\begin{tabular}{|c|c|c|c|c|c|}
\hline & \multirow{2}{*}{ All cases } & \multicolumn{3}{|c|}{ Neer classification } & \multirow{2}{*}{ p-value } \\
\hline & & Type II & Type III & Type IV & \\
\hline Head-Shaft angle $\left({ }^{\circ}\right)$ & $\begin{array}{c}133,4 \pm 10,1 \\
135[94-156]\end{array}$ & $\begin{array}{c}134,6 \pm 5,1 \\
136[125-142]\end{array}$ & $\begin{array}{c}132,6 \pm 9,4 \\
135[111-148]\end{array}$ & $\begin{array}{c}133,2 \pm 14,7 \\
135[94-156]\end{array}$ & $0,924^{a}$ \\
\hline Anterior/posterior ang $\left(^{\circ}\right)$ & $\begin{array}{c}-8,34 \pm 11,23 \\
-3[-38-8]\end{array}$ & $\begin{array}{c}-6,91 \pm 11,42 \\
-3[-28-5]\end{array}$ & $\begin{array}{c}-7,69 \pm 12,73 \\
-2[-38-8]\end{array}$ & $\begin{array}{c}-10,55 \pm 9,78 \\
-4[-24-0]\end{array}$ & $0,375^{\circ}$ \\
\hline Major tuberosity reduction (mm) & $\begin{array}{c}-0,93 \pm 4,05 \\
0[-9-8]\end{array}$ & NA & $\begin{array}{c}-0,59 \pm 3,07 \\
0[-8-3,8]\end{array}$ & $\begin{array}{c}-1,34 \pm 5,11 \\
0[-9-8]\end{array}$ & $0,664^{b}$ \\
\hline Plate height (mm) & $\begin{array}{l}-8,70 \pm 5,19 \\
-9,7[-20-2]\end{array}$ & $\begin{array}{c}-9,91 \pm 3,37 \\
-10[-16,4--5,03]\end{array}$ & $\begin{array}{c}-9,55 \pm 6,38 \\
-10,8[-20-2]\end{array}$ & $\begin{array}{l}-8,70 \pm 5,19 \\
-9,7[-20-2]\end{array}$ & $0,231^{b}$ \\
\hline
\end{tabular}


$(P<0.005)$ decrease in the Constant score relative to the contralateral limb (Constant 85.8 \pm 6.1 ).

In the multiple linear regression analysis, Neer IV fractures explained $30.7 \%(P=0.001)$ and $17.9 \%(P=0.013)$ of the variation in the Constant and DASH scores, respectively. Age, sex, affected side, occurrence of osteonecrosis, fracture consolidation angle, and plate height were not significantly associated with these scores. The presence of a Neer IV fracture led to a 19 point decrease in the Constant score $(P=0.001)$ and a 13.6 point increase in the Dash score $(P=0.013)$ postoperatively. (Table 4)

\section{DISCUSSION}

The incidence of proximal humerus fractures has increased in recent decades with the increasing elderly population. Consistent with the literature, we observed a higher incidence of fractures in patients over 50 years and in women. ${ }^{14}$

Consolidation with a change in the head-shaft angle occurred in $15 \%$ of the patients in comparison with a reported incidence of $0-21 \%{ }^{15-17}$ However, we observed a greater frequency of valgus than varus consolidation. The postoperative varus collapse of the humeral head in patients undergoing osteosynthesis with a locking

Table 3. Categorical variables (frequency).

\begin{tabular}{|c|c|c|c|c|c|}
\hline & \multirow{2}{*}{$\begin{array}{l}\text { All cases } \\
(n=35)\end{array}$} & \multicolumn{3}{|c|}{ Neer classification } & \multirow[b]{2}{*}{$p$-value } \\
\hline & & $\begin{array}{l}\text { Type II } \\
(n=11)\end{array}$ & $\begin{array}{l}\text { Type III } \\
(n=13)\end{array}$ & $\begin{array}{c}\text { Type IV } \\
(n=11)\end{array}$ & \\
\hline \multicolumn{5}{|l|}{ Head-Shaft angle } & \multirow{4}{*}{0.908} \\
\hline $\operatorname{Varus}\left(<120^{\circ}\right)$ & $5.7 \%(2 / 35)$ & $0 \%(0 / 11)$ & $7.7 \%(1 / 13)$ & $9.1 \%(1 / 11)$ & \\
\hline Normal $\left(120^{\circ}\right.$ to $\left.140^{\circ}\right)$ & $\begin{array}{r}85.7 \% \\
(30 / 35) \\
\end{array}$ & $\begin{array}{r}90.9 \% \\
(10 / 11) \\
\end{array}$ & $\begin{array}{r}84.6 \% \\
(11 / 13) \\
\end{array}$ & $\begin{array}{l}81.8 \% \\
(9 / 11) \\
\end{array}$ & \\
\hline Valgus $\left(>140^{\circ}\right)$ & $8.6 \%(3 / 35)$ & $9.1 \%(1 / 11)$ & $7.7 \%(1 / 13)$ & $9.1 \%(1 / 11)$ & \\
\hline \multicolumn{5}{|l|}{$\begin{array}{c}\text { Anterior/posterior } \\
\text { angulation }\end{array}$} & \multirow{4}{*}{0.628} \\
\hline Posterior $\left(<-5^{\circ}\right)$ & $\begin{array}{l}34.3 \% \\
(12 / 35)\end{array}$ & $\begin{array}{l}27.3 \% \\
(3 / 11)\end{array}$ & $\begin{array}{l}30.8 \% \\
(4 / 13)\end{array}$ & $\begin{array}{l}45.5 \% \\
(5 / 11)\end{array}$ & \\
\hline Normal $\left(-5^{\circ}\right.$ to $\left.+5^{\circ}\right)$ & $\begin{array}{l}62.9 \% \\
(22 / 35)\end{array}$ & $\begin{array}{l}72.7 \% \\
(8 / 11)\end{array}$ & $\begin{array}{l}61.5 \% \\
(8 / 13)\end{array}$ & $\begin{array}{l}54.5 \% \\
(6 / 11)\end{array}$ & \\
\hline Anterior $\left(>+5^{\circ}\right)$ & $2.9 \%(1 / 35)$ & $0 \%(0 / 11)$ & $7.7 \%(1 / 13)$ & $0 \%(0 / 11)$ & \\
\hline \multicolumn{5}{|l|}{$\begin{array}{l}\text { Greater tuberosity } \\
\text { reduction }\end{array}$} & \multirow{3}{*}{0.647} \\
\hline Below & $\begin{array}{l}45.8 \% \\
(11 / 24) \\
\end{array}$ & NA & $\begin{array}{l}46.2 \% \\
(6 / 13) \\
\end{array}$ & $\begin{array}{l}45.5 \% \\
(5 / 11) \\
\end{array}$ & \\
\hline Same or above & $\begin{array}{l}54.2 \% \\
(13 / 24)\end{array}$ & NA & $\begin{array}{l}53.8 \% \\
(7 / 13) \\
\end{array}$ & $\begin{array}{l}54.5 \% \\
(6 / 11) \\
\end{array}$ & \\
\hline \multicolumn{5}{|l|}{ Plate height } & \multirow{3}{*}{0.406} \\
\hline Below & $\begin{array}{c}91.4 \% \\
(32 / 35)\end{array}$ & $\begin{array}{c}100 \% \\
(11 / 11)\end{array}$ & $\begin{array}{l}84.6 \% \\
(11 / 13)\end{array}$ & $\begin{array}{r}90.9 \% \\
(10 / 11)\end{array}$ & \\
\hline Same or above & $8.6 \%(3 / 35)$ & $0 \%(0 / 11)$ & $\begin{array}{l}15.4 \% \\
(2 / 13)\end{array}$ & $9.1 \%(1 / 11)$ & \\
\hline
\end{tabular}

plate is related to both medial comminution of the humerus and to the absence of screw placement in the humeral calcar region. ${ }^{11,17,18}$ Therefore, we believe that we observed less varus consolidation compared with most reports in the literature because of our routine use of inferior screws in the humeral head, which was our practice even when it was necessary to put the plate more inferiorly. Metha et al. observed greater biomechanical stability with the plates placed more inferiorly, ${ }^{18}$ which also resulted in a lower incidence of secondary impingement compared with most reports in the literature. ${ }^{19}$ The higher incidence of valgus consolidation may also have occurred because reduction with a greater cervical-diaphyseal angle was used to facilitate the placement of the medial and inferior screws in the head, as we did not use implants with polyaxial screws. ${ }^{20}$

There were 12 cases of consolidation with posterior deviation of the head. The evaluation of postoperative anteversion / retroversion in proximal humerus fractures is poorly described in the literature. However, our results are similar to those using the anterolateral approach using the MIPO technique or the deltopectoral approach, and we relied on the posterior/anterior tilt of the humeral head as a means of evaluating the cephalic version in the axillary radiological view. ${ }^{11,12}$ The reduction of the greater tuberosity was above the surface of the humeral head in six patients (25\%) with Neer III and IV fractures. However, two cases were secondary to humeral head varus consolidation. Therefore, adequate reduction of the tuberosity was achieved in $83.3 \%$ of our cases. Malunion of the greater tuberosity should be avoided, as it may lead to secondary impingement and decreased shoulder function. ${ }^{12}$

In agreement with the literature, there was no statistical difference in the postoperative angulation according to the type of fracture as classified by Neer. ${ }^{12,19}$ However, the anatomical reduction of proximal humerus fractures remains challenging, regardless of the approach, and functional worsening of the shoulder occurs when reduction is not attained. ${ }^{19}$ Arthroplasty may be an option for elderly osteoporotic patients in whom adequate fracture reduction cannot be achieved. ${ }^{12}$ The reported incidence of osteonecrosis secondary to proximal humeral fracture ranges from 0 to $68 \%{ }^{9}$ There is a positive correlation between fracture type (Neer IV) and an increased chance of progression to osteonecrosis. ${ }^{11}$ Partial humeral head necrosis occurred in two of our patients (one each Neer IV and III). However, there was no correlation between the presence of osteonecrosis and a worse functional outcome. Head collapse and migration of the screw to the articular region result in a worse prognosis, but this occurred in only one patient, which could explain the absence of the influence of osteonecrosis on the functional evolution. However, our mean follow-up time was 31 months, and some authors report that the evolution to osteonecrosis occurred 36 months after treatment. ${ }^{9}$ Another limitation of the study was that it did not evaluate the influence of the Hertel criteria or medial comminution on osteonecrosis.

Pseudarthrosis has an incidence of $1-10 \%$, which is influenced by the type of fracture and smoking. ${ }^{19}$ We did not observe any pseudarthrosis.

Table 4. Multiple linear regression results

\begin{tabular}{|c|c|c|c|c|c|c|c|c|c|}
\hline Dependent Variable & Predictor & $\begin{array}{l}\text { Regression Coefficient } \\
\text { - Not standardised (B) }\end{array}$ & $\begin{array}{l}\text { Regression } \\
\text { Coefficient - }\end{array}$ & $p$-Value & \multicolumn{3}{|c|}{ IC $95 \%$ (B) } & $\begin{array}{l}\text { Variance explained } \\
\text { by the predictor (\%) }\end{array}$ & $\mathbf{R}^{2}$ \\
\hline $\begin{array}{l}\text { Constant Scores } \\
\text { (operated shoulder) }\end{array}$ & Constant value & 78.6 & & $<0.001$ & 72.7 & $a$ & 84.4 & 30.7 & 0.307 \\
\hline \multirow{2}{*}{$\begin{array}{c}\text { DASH Score } \\
\text { (operated shoulder) }\end{array}$} & Constant value & 7.0 & & 0.024 & 1.0 & a & 12.9 & \multirow[b]{2}{*}{17.9} & \multirow[b]{2}{*}{0.179} \\
\hline & $\begin{array}{l}\text { Neer Classification } \\
\text { (IV/others) }\end{array}$ & 13.6 & 0.42 & 0.013 & 3.1 & a & 24.09 & & \\
\hline
\end{tabular}


In one patient (2\%), migration of a screw into the joint progressed to osteonecrosis, requiring removal. Joint penetration by a screw is one of the main complications in the treatment of proximal humeral fractures with a locking plate, with a reported incidence of $1-13 \%$. Penetration may be related to inadequate intraoperative positioning or may be secondary to humeral head collapse due to osteonecrosis or varus consolidation. ${ }^{18}$

There were no postoperative neurological changes. Theoretically, the anterolateral approach poses a greater risk to the axillary nerve. However, studies susing the MIPO technique did not observe damage to this structure.12

With the MIPO technique, there is no direct approach to or isolation of the axillary nerve. However, the use of the last two proximal rows in the plate should be avoided because of their proximity to the nerve. ${ }^{18}$ Gardner pioneered the use of an anterolateral approach with direct exposure of the axillary nerve and did not observe iatrogenic injury of this structure. This approach has the advantage of using all the screws, as the nerve is isolated. The use of the inferior screw in the calcar region adds mechanical stability to the fracture, preventing collapse of the humeral head. ${ }^{18}$ As reported by Gardner, we observed no axillary lesion. Additionally, although we examined the dermatome for the axillary nerve only postoperatively, pre- and postoperative electromyography is the gold standard for evaluating the axillary nerve. ${ }^{16}$ The functional evaluation was performed using the Constant and DASH scores. The average Constant score was $72.1 \pm 16.2$, which reflected significantly reduced function compared with the contralateral shoulder. Numerous studies have shown a decrease in shoulder function after osteosynthesis. ${ }^{19}$ The DASH score was $12.1 \pm 15.7$, which is similar to reports in the literature and reflects a satisfactory postoperative functional result. The only factor that correlated with a worsening of the functional scores was the type of fracture: Neer IV fractures were associated with a significant worsening of the functional score. In general, four-part fractures are associated with rotator cuff involvement and consequent functional worsening. ${ }^{12}$ Our results are in agreement with the literature, although the majority of these studies performed the osteosynthesis using the deltopectoral approach or MIPO technique. ${ }^{17}$

Therefore, despite not being a comparative study, our functional results and complication rates were similar to those found in studies of patients undergoing osteosynthesis of proximal humerus fractures with locking plate that used the deltopectoral approach or split the deltoid using the MIPO technique. To date, few studies have evaluated the extended anterolateral approach in the treatment of proximal humerus fractures. ${ }^{14,17}$ We hope to contribute to knowledge in this area by increasing the number of patients surgically treated with this approach. A randomised study comparing all approaches would be ideal for comparing the results.

\section{CONCLUSION}

The treatment of proximal humerus fractures with locking plate using the extended anterolateral approach gave good functional results, although function was decreased, especially in patients with Neer IV fractures. The main complication was malunion. There were no side effects due to exposure of the axillary nerve.

AUTHORS' CONTRIBUTIONS: Each author contributed individually and significantly to the development of the article. Main contributions: Study design: GGM (0000-0002-8258-5350)* , ME (0000-0002-5176-2369)*: Statistical analysis: LM (0000-0002-6584-5333)*, GGM (0000-0002-8258-5350)*; Selection of manuscripts and final revision: FKK (0000-0002-1409-2124)*, AZF (0000-0002-8704-8378)*, PPSJ (0000-0001-6078-0975)*, ME(0000-0002-5176-2369)* LM (0000-0002-6584-5333)*, GGM (0000-0002-8258-5350)*. All authors have revised and approved the final version of the manuscript. *ORCID (Open Researcher and Contributor ID).

\section{REFERENCES}

1. Thanasas C, Kontakis G, Angoules A, Limb D, Giannoudis P. Treatment of proximal humerus fractures with locking plates: A systematic review. J Shoulder Elb Surg. 2009;18(6):837-44

2. Chou YC, Tseng IC, Chiang CW, Wu CC. Shoulder hemiarthroplasty for proxima humeral fractures: Comparisons between the deltopectoral andanterolateral deltoid-splitting approaches. J Shoulder Elb Surg. 2013;22(8):e1-7.

3. Südkamp N, Bayer J, Hepp P, Voigt C, Oestern H, Kääb M, et al. Open Reduction and Internal Fixation of Proximal Humeral Fractures with Use of the Locking Proximal Humerus Plate. J Bone Jt Surg Am. 2009;91(6):1320-8.

4. Brunner A, Thormann S, Babst R. Minimally invasive percutaneous plating of proximal humeral shaft fractures with the Proximal Humerus Internal Locking System (PHILOS). J Shoulder Elb Surg. 2012;21(8):1056-63.

5. Gardner MJ, Griffith MH, Dines JS, Lorich DG. A minimally invasive approach for plate fixation of the proximal humerus. Bull Hosp Jt Dis. 2004;62(1-2):18-23.

6. Stecco C, Gagliano G, Lancerotto L, Tiengo C, Macchi V, Porzionato A, et al. Surgical anatomy of the axillary nerve and its implication in the transdeltoid approaches to the shoulder. J Shoulder Elb Surg. 2010;19(8):1166-74.

7. Burkhead WZ, Scheinberg RR, Box G. Surgical anatomy of the axillary nerve. J Shoulder Elb Surg. 1992;1(1):31-6.

8. Rancan M, Dietrich M, Lamdark T, Can U, Platz A. Minimal invasive long PHILOS??-plate osteosynthesis in metadiaphyseal fractures of the proximal humerus. Injury. 2010;41(12):1277-83.

9. Shin SJ, Kim JK, Koh YW. Minimally Invasive Plate Osteosynthesis for Proxima Humeral Fractures: A Prospective Study of Clinical and Radiological Outcomes According to Fracture Type. J Shoulder Elb Surg. 2015;24(8):e229.

10. Laflamme GY, Rouleau DM, Berry GK, Beaumont PH, Reindl R, Harvey EJ. Percutaneous Humeral Plating of Fractures of the Proximal Humerus: Results of a Prospective Multicenter Clinical Trial. J Orthop Trauma. 2008;22(3):153-8. 11. Hirschmann MT, Quarz V, Audigé L, Ludin D, Messmer P, Regazzoni P, et al. Internal fixation of unstable proximal humerus fractures with an anatomically preshaped interlocking plate: A clinical and radiologic evaluation. J Trauma 2007;63(6):1314-23

12. Sohn H-S, Jeon YS, Lee J, Shin S-J. Clinical comparison between open plating and minimally invasive plate osteosynthesis for displaced proximal humeral fractures: A prospective randomized controlled trial. Injury. 2017;48(6):1175-82.

13. Constant CR, Gerber C, Emery RJH, Ed F. A review of the Constant score : Modifications and guidelines for its use. J Shoulder Elbow Surg. 2008;17(2):355-61.

14. Gardner MJ, Boraiah S, Helfet DL, Lorich DG. The anterolateral acromial approach for fractures of the proximal humerus. J Orthop Trauma. 2008;22(2):132-7.

15. Buecking B, Mohr J, Bockmann B, Zettl R, Ruchholtz S. Deltoid-split or deltopectoral approaches for the treatment of displaced proximal humeral fractures? Clin Orthop Relat Res. 2014;472(5):1576-85.

16. Fischer C, Frank M, Kunz P, Tanner M, Weber MA, Moghaddam A, et al. Dynamic contrast-enhanced ultrasound (CEUS) after open and minimally invasive locked plating of proximal humerus fractures. Injury. 2016;47(8):1725-31.

17. Wu CH, Ma CH, Yeh JJH, Yen CY, Yu SW, Tu YK. Locked plating for proximal humeral fractures: Differences between the deltopectoral and deltoid-splitting approaches. J Trauma. 2011;71(5):1364-70.

18. Mehta S, Chin M, Sanville J, Namdari S, Hast MW. Calcar screw position in proximal humerus fracture fixation: Don't miss high! Injury. 2018;49(3):624-9.

19. Sproul RC, lyengar JJ, Devcic Z, Feeley BT. A systematic review of locking plate fixation of proximal humerus fractures. Injury. 2011;42(4):408-13.

20. Barco R, Barrientos I, Encinas C, Antuña SA. Minimally invasive poly-axial screw plating for three-part fractures of the proximal humerus. Injury. 2012;43(Suppl 2):7-11. 